\title{
Interleukin-12 Peripheral Blood Levels in Asthmatic Children
}

\author{
Ruth Soferman, $M D$, Idit Rosenzwig, MD, and Elizabeth Fireman, PhD
}

\begin{abstract}
Interleukin-12 (IL-12) was measured in 45 asthmatic children aged 3 to 16 years. The assessments were performed on 20 children during an episode of acute exacerbation and on 25 children during remission. There was no significant difference between the mean IL-12 level during exacerbation $(1.63 \pm 2.08 \mathrm{pg} / \mathrm{mL})$ and during remission $(0.88 \pm 0.56 \mathrm{pg} / \mathrm{mL})(p=.83)$. A positive, but insignificant, correlation was found between forced expiratory volume in 1 second and IL-12 ( $p=.634)$. IL-12 levels were significantly lower in children with a positive family history of asthma $(1.13 \pm 1.78 \mathrm{pg} / \mathrm{mL})$ compared with those without $(1.31 \pm 1.06 \mathrm{pg} / \mathrm{mL})(p<.012)$, supporting the theory that the gene-environment interactions affect the immune responses. IL-12 peripheral blood levels had no detectable impact on the course of established asthma in the study population.
\end{abstract}

Key words: asthma, family history, IL-12

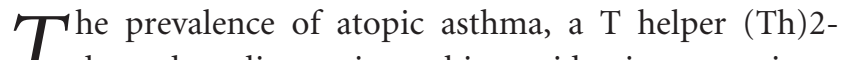
1 dependent disease, is reaching epidemic proportions, possibly owing to improved hygiene in industrialized countries. ${ }^{1}$ The chronic inflammation of the airways in asthma is characterized by the presence of Th2 cells in sputum, bronchoalveolar lavage, and mucosal biopsy specimens, ${ }^{2}$ and the dominance of Th2 cells is responsible for the pathogenesis of allergic diseases. ${ }^{3-6}$ The priming of $\mathrm{T}$ cells requires the activation of dendritic cells (DCs), ${ }^{7}$ which are generally considered to be the principal antigenpresenting cells (APCs) involved in the generation of polarized effector cells. ${ }^{4}$ DCs have a major influence on the pattern of Th1/Th2 polarization by releasing cytokines, especially interleukin-12 (IL-12). ${ }^{5}$ The route of the antigen encounter with the DC and the subtype of the APC can profoundly influence Th differentiation. ${ }^{7}$ IL-12, the critical Th1-polarizing cytokine ${ }^{8}$ produced by DCs after stimulation by various antigens, including the endotoxin lipopolysaccharide (LPS), which is derived from the cell walls of gram-negative bacteria ${ }^{9}$ and it is ubiquitous in the

Ruth Soferman: Pediatric Pulmonology Unit; Idit Rosenzwig: Department of Pediatrics, Dana Children's Hospital; and Elizabeth Fireman: Laboratory of Pulmonary and Allergic Diseases, Tel Aviv Sourasky Medical Center, Sackler Faculty of Medicine, Tel Aviv University, Tel Aviv, Israel.

Correspondence to: Dr. Ruth Soferman, Pediatric Pulmonology Unit, Dana Children's Hospital, Tel Aviv Sourasky Medical Center, 6 Weizman Street, Tel Aviv 64239, Israel; e-mail: soferman@post.tau.ac.il.

DOI $10.2310 / 7480.2007 .00010$ domestic environment. ${ }^{10}$ The functional active form of IL12 is a heterodimer composed of two disulphide-linked chains, p35 and p40, secreted by APCs ${ }^{11}$ and by activated Th1 cells; this heterodimer downregulates Th2 responses. ${ }^{12}$

Studies in asthma models concluded that the administration of IL-12 before and during the period of allergen challenge prevented allergen-induced airway eosinophilia, airway hyperresponsiveness, the production of Th2 cytokines, and the production of allergen-specific serum immunoglobulin $\mathrm{E},{ }^{13}$ whereas it increased the production of interferon- $\gamma$ and enhanced apoptosis of $\mathrm{CD} 4^{+} \mathrm{T}$ cells in allergic airway infiltrates. ${ }^{14}$

The main aim of the current study was to assess the relationship of IL-12 peripheral blood levels and the two states of asthma, acute exacerbation and remission, as demonstrated by the kinetics of DC activation by environmental stimuli and, consequently, Th1/Th2 polarization.

\section{Patients and Methods}

\section{Patients}

The study was conducted between April 2004 and September 2005 after having been approved by the local institutional review board (Helsinki Committee). The parents of all of the participants provided written informed consent.

The study population included 45 asthmatic children, aged 3 to 16 years (median age $9.5 \pm 3.4$ years), who were 
recruited from the pediatric emergency department and the pediatric pulmonology outpatient clinic. The inclusion criteria were a diagnosis of asthma prior to study entry confirmed by a pediatric pulmonologist and being treated by inhaled corticosteroids for at least the two previous months. The exclusion criteria were evidence of pneumonia on the chest radiograph, fever, already being treated by rescue medication ( $\beta_{2}$ agonists and systemic steroids), and having a chronic or acute illness other than asthma.

The participants were divided into two groups. Group A consisted of 20 children who were recruited when they arrived to the emergency department or to the outpatient clinic during an acute exacerbation of asthma. Group B included 25 asthmatic children who visited the outpatient clinic for a regular follow-up evaluation and were in remission.

The demographic information on the participants is presented in Table 1.

\section{Respiratory Symptoms and Asthma}

In the study children $\geq 6$ years of age, diagnosis of asthma prior to recruitment was by clinical parameters and by demonstrating bronchial hyperreactivity in pulmonary function tests with a provocation by either exercise or the adenosine test. Children younger than 6 years were diagnosed by clinical parameters, including a history of recurrent episodes of coughing, wheezing, and breathlessness that were relieved by bronchodilators and steroids.

The following data were collected for each patient: respiratory symptoms throughout the 2 months prior to the current presentation, the regular treatment regimen during the past few months, a family history of asthma and other diseases, smoking habits of family members, and the presence of pets at home. A comprehensive physical examination included the measurement and recording of weight, height, respiratory rate, heart rate, and oxygen saturation. Respiratory symptoms were evaluated according to respiratory rate, respiratory chest recession, auscultatory breath sounds, and general condition. Acute exacerbation was defined by the presence of coughing, tachypnea according to age, ${ }^{15}$ respiratory muscle retractions, and auscultatory findings of wheezing with prolonged expiration. Remission was defined when the child was free of cough for at least 2 weeks, the respiratory rate was $\leq 20$ breaths/minute, there were no respiratory muscle retractions, and normal breath sounds were heard on auscultation.

\section{Lung Function Tests}

Spirometry was performed by a Vitalograph compact II spirometer (Vitalograph Ltd., UK) in patients older than 6 years. The predicted results were analyzed according to Polgar normative data. ${ }^{16}$

\section{IL-12 Measurements}

IL-12 levels in serum samples were analyzed in duplicate using a commercial kit: Quantikine high sensitivity human IL-12 immunoassay (catalogue number HS120, R\&D Systems Inc., Minneapolis, MN). The Quantikine highsensitivity immunoassay kit uses an amplification system in which the alkaline phosphatase reaction provides a cofactor that activates a redox cycle leading to the formation of a coloured product. The minimum detectable dose of human IL-12 is typically less than $0.5 \mathrm{pg} / \mathrm{mL}$. This assay employs the quantitative sandwich enzyme immunoassay technique. A monoclonal antibody specific for IL12 has been precoated onto a microplate. Standards and samples are pipetted into the wells, and any IL-12 present is bound by the immobilized antibody. After washing away any unbound substances, an enzyme-linked polyclonal antibody specific for IL-12 is added to the wells. Following

Table 1. Demographic Data on the Two Groups of Study Children

\begin{tabular}{lccl}
\hline Demographic Data & Group A $(\mathrm{n}=20)$ & Group B $(\mathrm{n}=25)$ & $\mathrm{p}$ Value (Test) \\
\hline Males/females & $13 / 7$ & $19 / 6$ & .42 (chi-square) \\
Median current age (yr) & $8.2 \pm 3.1$ & $10.5 \pm 3.3$ & .05 (Mann-Whitney) \\
Family history of asthma & $12(60 \%)$ & $12(48 \%)$ & .42 (two-way ANOVA) \\
Passive smoking & $8(40 \%)$ & $7(28 \%)$ & .4 (chi-square) \\
Pets at home & $6(30 \%)$ & $8(32 \%)$ & .89 (chi-square) \\
Inhaled corticosteroids & & & .52 (Fisher exact test) \\
Budesonide & $10(45 \%)$ & $12(48 \%)$ & \\
Fluticasone & $11(55 \%)$ & $13(52 \%)$ & \\
\hline
\end{tabular}

ANOVA $=$ analysis of variance. 
a wash to remove any unbound antibody-enzyme reagent, a substrate solution is added to the wells. After an incubation period, an amplifier solution is added to the wells and colour develops in production to the amount of IL-12 bound in the initial step. The colour development is stopped, and the intensity of the colour is measured.

\section{Statistical Methods}

The assumption of normal distribution of continuous parameters was examined using the Kolmogorov-Smirnov and Wilk-Shapiro tests. Since the IL-12 levels were not distributed normally, we also analyzed the reciprocal transformation of this parameter to confirm the results. Comparisons between the two groups of patients for demographic parameters (gender, age, passive smoking, family history of asthma, and pet at home) and other factors (IL-12, forced expiratory volume in 1 second $\left[\mathrm{FEV}_{1}\right]$ measures) were performed using the $t$-test for independent samples, the Mann-Whitney nonparametric test, and the chi-square test, as applicable. In addition, a two-way analysis of variance (ANOVA) was performed to examine the association between each group's family history of asthma and IL-12 levels. Spearman nonparametric correlation coefficients were calculated to study the relationship between all continuous parameters and IL-12. Significance was set at $p=.05$, and SPSS for Windows software version 13.0 (SPSS Inc, Chicago, IL) was used for the analysis.

\section{Results}

The patient population consisted of 45 children clinically diagnosed as being asthmatic: 20 were studied during an acute episode of asthma (group A) and 25 were studied during a remission (group B). There were no significant differences between the two study groups in terms of the male to female ratio, pets at home, passive smoking, and family history of asthma (see Table 1).

The median age of the children in group A $(8.21 \pm 3.16$ years) was significantly lower than the median age of the children in group B $(10.52 \pm 3.33, p<.025)$, but this difference had no impact on the IL-12 analysis between two groups.

The mean IL-12 level was $1.63 \pm 2.08 \mathrm{pg} / \mathrm{mL}$ (range $0.3-8.3 \mathrm{pg} / \mathrm{mL}$ ) in group A and $0.88 \pm 0.56 \mathrm{pg} / \mathrm{mL}$ (range $0.4-3.2 \mathrm{pg} / \mathrm{mL}$ ) in group $\mathrm{B}$; the difference between the two groups was not significant ( $t$-test $p=1.0$ and MannWhitney test $p=.83$ ). The IL-12 levels in both groups were significantly lower in children with a positive family history of asthma compared with children without. The mean blood level of IL-12 was $1.13 \pm 1.78 \mathrm{pg} / \mathrm{mL}$ in children with a family history of asthma and $1.31 \pm 1.06$ $\mathrm{pg} / \mathrm{mL}$ in children without a family history of asthma (two-way ANOVA test $p<.012$ ) (Figure 1).

Plotting the related percent predicted values of $\mathrm{FEV}_{1}$ to IL-12 levels demonstrated a positive correlation between $\mathrm{FEV}_{1}$ and IL-12: higher IL-12 levels were correlated to the higher percent predicted values of $\mathrm{FEV}_{1}$ (Figure 2). These positive correlations did not, however, reach a level of significance (Spearman correlation coefficient, $p=.634$ ).

\section{Discussion}

The findings of this study demonstrated that there were no significant differences between the mean peripheral blood levels of IL-12 during asthma exacerbation and those during remission. Thus, IL-12 peripheral blood levels do not reflect the state of asthma. Although the children who were tested during an acute attack were significantly younger than the children who were tested while in remission, Tomita and colleagues reported that age plays no role in the production of IL-12. ${ }^{17}$ We cannot provide an explanation for the unexpected results, and further clinical studies are needed to elucidate them.

\section{IL-12 levels and family $\mathrm{Hx}$ of asthma}

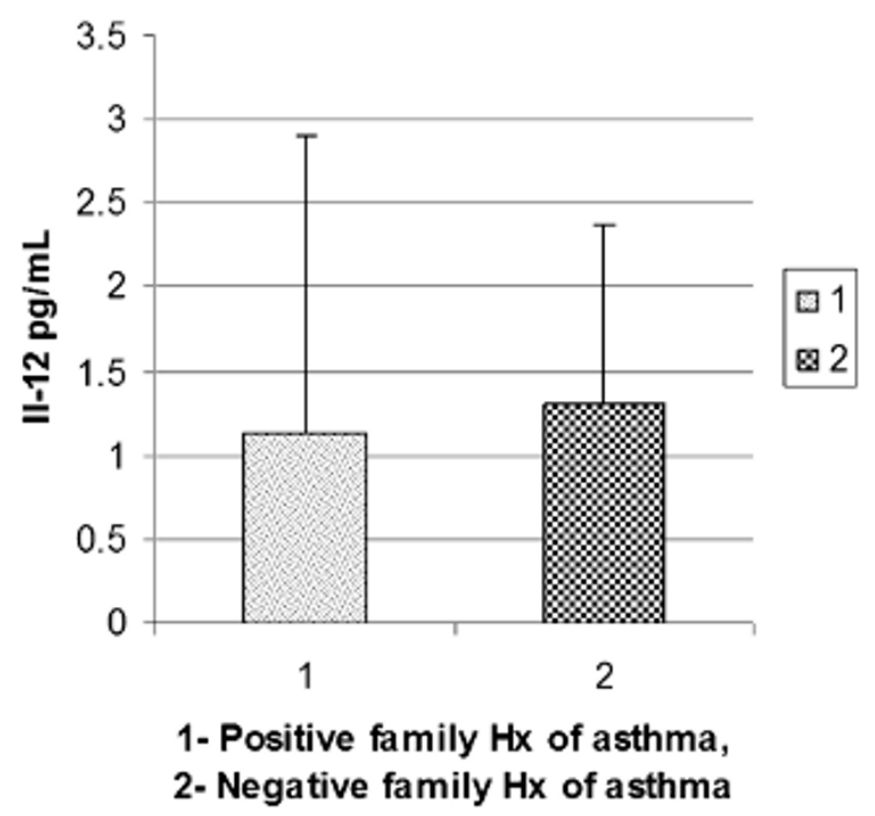

Figure 1. Correlation of interleukin-12 levels to family history (Hx) of asthma. $p<.012$ (two-way ANOVA test). 


\section{IL-12 vs. FEV1\%}

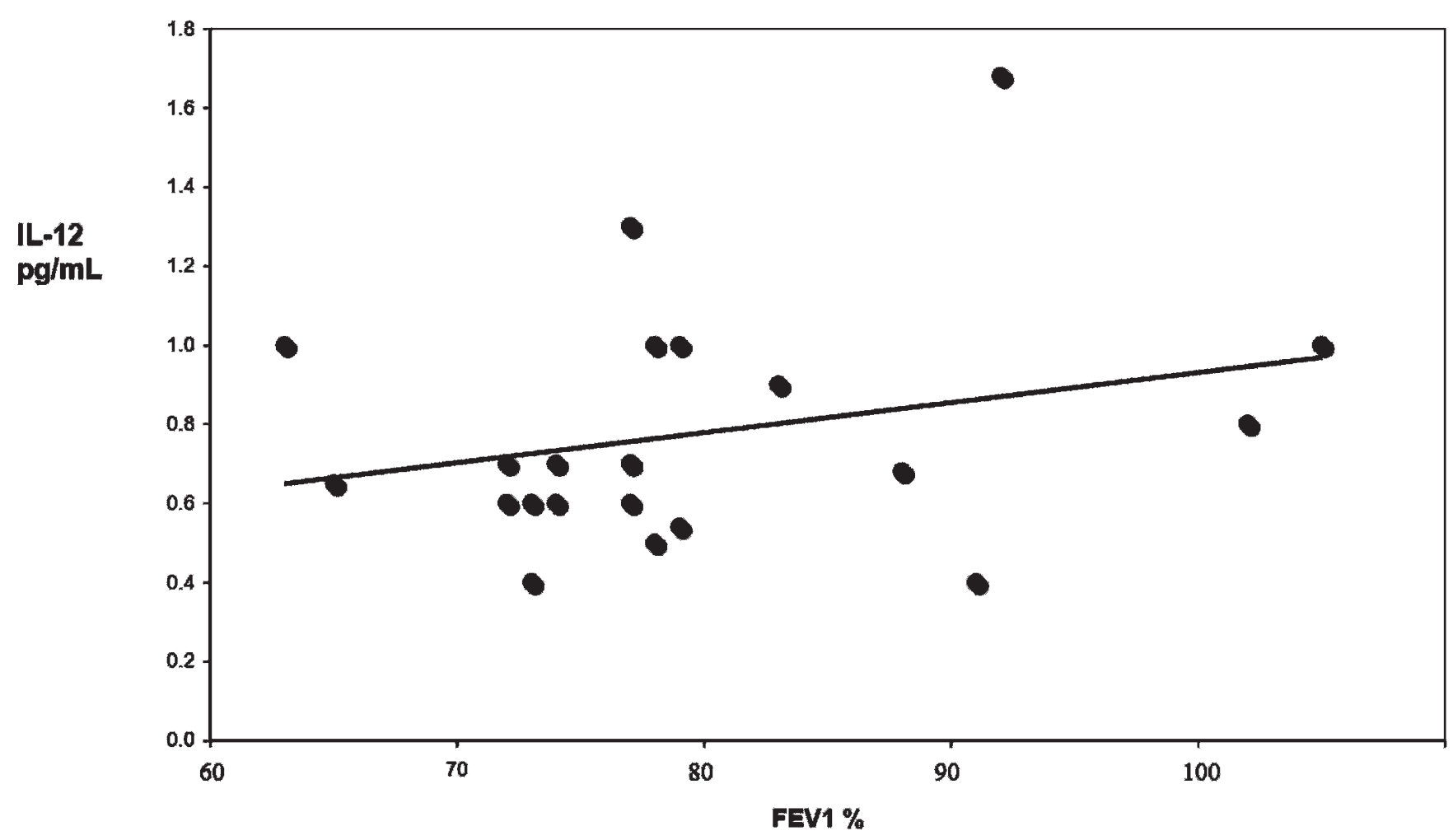

Figure 2. Interleukin-12 (IL-12) peripheral blood levels versus forced expiratory volume in 1 second percent $\left(\mathrm{FEV}_{1} \%\right)$ predicted values. There were positive correlations between $\mathrm{FEV}_{1} \%$ predicted values and IL-12 peripheral blood levels, but they did not reach a level of significance $(p=.6)$.

All of the participants were treated by inhaled corticosteroids. Since there are no publications of a direct influence of inhaled corticosteroids on IL-12 blood levels, we presume that the inhaled corticosteroids were not an influencing factor on these results.

IL-12, a critical Th1 polarizing cytokine ${ }^{8}$ and a heterodimer ${ }^{18}$ produced mainly by DCs and Th1 cells, has been shown to have potent immune activity by inducing Th1 responses, suppressing Th2 responses, and enhancing apoptosis of $\mathrm{CD} 4^{+} \mathrm{T}$ cells in allergic airways. ${ }^{14}$ An exogenous form of IL-12 given to a mouse model reduced established airway responses, such as eosinophilic infiltration and airway hyperresponsiveness. ${ }^{19}$ Endotoxins, which are inflammatory LPS molecules derived from a gram-negative bacteria wall, are ubiquitous in the indoor environment, ${ }^{20}$ and significantly associated with pets at home. ${ }^{21} \mathrm{~A}$ bimodal, dose-dependent relationship between environmental exposure to LPS and the presence of immune responses supports the hygiene theory by demonstrating a preponderance of Th2 at low LPS exposure and a preponderance of Th1 at high LPS exposure. ${ }^{22}$ Gereda and colleagues suggested that indoor endotoxin exposure early in life may protect against allergen sensitization. ${ }^{23}$ Inhaled endotoxins trigger macrophages and other myeloid cells, including myeloid DCs, through CD14, a LPS-binding protein, to release cytokines, including IL-12. ${ }^{24}$ IL-12 redirects the Th cells responses toward the Th1 immune response. ${ }^{25}$ Asthmatic patients with severe airflow obstruction showed an impairment of IL-12 production. ${ }^{26}$ A study of peripheral blood mononuclear cells showed that severe asthmatics had significantly less positive staining for IL-12 after stimulation with LPS compared with mild asthmatics and controls. ${ }^{17}$ The genetic predisposition that determines the effect of environmental endotoxins and allergic reactions and the production of IL-12 was influenced by the polymorphism in the CD14 gene. ${ }^{27}$ In opposition to all of the abovecited reports, the study of the national survey of endotoxins in US housing demonstrated that household endotoxin exposure is a significant risk factor for increased asthma symptoms and wheezing. ${ }^{28}$ Braun-Fahrlander and colleagues claimed that exposure to endotoxins at school age was an increased risk factor for asthma exacerbations. $^{29}$ 
Blockade of IL-12 was recently demonstrated in an animal model to have differential effects on allergic airway inflammation, depending on the timing of the blockade. Blocking IL-12 during the sensitization process aggravated the subsequent development of allergic airway inflammation, whereas neutralization of IL-12 during the challenge phase in previously sensitized mice abolished eosinophilic airway inflammation. ${ }^{30}$

The significantly lower mean level of IL-12 in children with a positive family history of asthma compared with the higher mean level in children without a positive family history supports the theory that the gene-environment interactions affect the immune responses. ${ }^{31}$ Moreover, higher IL-12 levels correlated with higher $\mathrm{FEV}_{1}$ levels, although not significantly so. In conclusion, we found no relationship between IL-12 peripheral blood levels and the course of established asthma in asthmatic children aged 3 to 16 years. The small cohort of children precludes our arriving at any firm conclusions, so we recommend larger clinical studies to validate our findings.

\section{Acknowledgements}

We thank Mr. Doron Comaneshter from the statistical service of the Tel Aviv Sourasky Medical Center for his help in statistical analysis and Mrs. Esther Eshkol for her valuable assistance in revising the manuscript.

\section{References}

1. Umetsu DT, McIntire JJ, Akbari O, et al. Asthma: an epidemic of dysregulated immunity. Nat Immunol 2002;3:715-20.

2. Mori A, Ogawa K, Kajiyama Y, et al. Th2-cell-mediated chemokine synthesis is involved in allergic airway inflammation in mice. Int Arch Allergy Immunol 2006;140:55S-8S.

3. Plummeridge MJ, Armstrong L, Birchall MA, Millar AB. Reduced production of interleukin 12 by interferon- $\gamma$ primed alveolar macrophages from atopic asthmatic subjects. Thorax 2000;55:8427.

4. Moser M, Murphy KM. Dendritic cell regulation of TH1-TH2 development. Nat Immunol 2000;1:199-205.

5. Prescott SL, Taylor A, King B, et al. Neonatal interleukin-12 capacity is associated with variation in allergen-specific immune responses in the neonatal and post natal periods. Clin Exp Allergy 2003;33:566-72.

6. Lambrecht BN, De Veerman A, Coyle AJ, et al. Myeloid dendritic cells induce Th2 responses to inhaled antigen, leading to eosinophilic airway inflammation. J Clin Invest 2000;106:551-9.

7. Banchereau J, Steinman RM. Dendritic cells and the control of immunity. Nature 1998;392:245-52.

8. Trinchieri G. Interleukin-12: a proinflammatory cytokine with immunoregulatory functions that bridge innate resistance and antigen-specific adaptive immunity. Annu Rev Immunol 1995;13: $251-76$.
9. Milton DK, Johnson DK, Park JH. Environmental endotoxin measurement: interference and sources of variation in the Limulus assay of house dust. Am Ind Hyg Assoc J 1997;58:861-7.

10. Macatonia SE, Hosken NA, Litton M, et al. Dendritic cells produce IL-12 and direct the development of Th1 cells from naïve CD4+ T cells. J Immunol 1995;154:5071-9.

11. Shu U, Kiniwa $\mathrm{M}, \mathrm{Wu} \mathrm{CY}$, et al. Activated $\mathrm{T}$ cells induce inteleukin-12 production by monocytes via CD40-CD40 ligand interaction. Eur J Immunol 1995;25:1125-8.

12. Jirapongsananuruk O, Leung DY. Clinical application of cytokines: new direction in the therapy of atopic diseases. Annu Allergy Asthma Immunol 1997;79:5-20.

13. Sur S, Lam J, Bouchard P, et al. Immunomodulatory effects of IL12 on allergic lung inflammation depend on timing of doses. J Immunol 1996;157:4173-80.

14. Kodama T, Kuribayashi K, Nakamura H, et al. Role of interleukin12 in the regulation of CD4+ T cell apoptosis in a mouse model of asthma. Clin Exp Immunol 2003;131:199-205.

15. Mathers LH, Frankel LR. Pediatric emergencies and resuscitation. In: Behrman RE, Kliegman RM, Jenson HB, editors. Nelson textbook of pediatrics. Philadelphia: Saunders; 2004. p. 280.

16. Quanjer PH, Borsboom GJ, Brunekreff B, et al. Spirometric reference values for white European children and adolescents: Polgar revisited. Pediatr Pulmonol 1995;19:135-42.

17. Tomita K, Lim S, Hanazawa T, et al. Attenuated production on intracellular IL-10 and IL-12 in monocytes from patients with severe asthma. Clin Immunol 2002;102:258-66.

18. Trinchieri G, Pflanz S, Kastelein RA. The IL-12 family of heterodimeric cytokines: new players in the regulation of $\mathrm{T}$ cell responses. Immunity 2003;19:641-4.

19. Kuribayashi K, Kodama T, Okamura H, et al. Effects of post inhalation treatment with interleukin (IL)-12 on airway hyperreactivity, eosinophilia, and IL-18 receptor expression in mouse model of asthma. Clin Exp Allergy 2002;32:641-9.

20. Thorne PS, Heederic D. Indoor bioacrosols: sources and characteristics. In: Satthammer T, editor. Organic indoor air pollutants: occurrence, measurement, evacuation. Weinheim (Germany): Wiley - VCH; 1999. p. 275-88.

21. Park JH, Spiegelman DL, Gold DR, et al. Predictors of airborne endotoxin in the home. Environ Health Perspect 2001;109:859-64.

22. Vercelli D. Learning from discrepancies: CD14 polymorphisms, atopy and endotoxins switch. Clin Exp Allergy 2003;33:153-5.

23. Gereda JE, Leung DY, Thatayatikom A, et al. Relation between house dust endotoxin exposure, type $1 \mathrm{~T}$-cell development, and allergen sensitisation in infants at high risk of asthma. Lancet 2000; 355:1680-3.

24. Tobias PS, Tapping RI, Gegner JA. Endotoxin interactions with lipopolysaccharide-responsive cells. Clin Infect Dis 1999;28:47681.

25. Manetti R, Parronchi P, Giudizi MG, et al. Natural killer cell stimulatory factor (interleukin 12 [IL-12]) induces T helper type 1 (Th1)-specific immune responses and inhibits the development of IL-4 producing Th cells. J Exp Med 1993;117:1199-204.

26. Naseer T, Minshall EM, Leung DY, et al. Expression of IL-12 and IL-13 mRNA in asthma and their modulation response to steroid therapy. Am J Respir Crit Care Med 1997;155:845-51.

27. Simpson A, John SL, Jury F, et al. Endotoxin exposure, CD14, and allergic disease. An interaction between genes and the environment. Am J Respir Crit Care Med 2006;174:386-92. 
28. Thorne PS, Kulhankova K, Yin M, et al. Endotoxin exposure is a risk factor for asthma. The national survey of endotoxins in United States housing. Am J Respir Crit Care Med 2005;172:1371-7.

29. Braun-Fahrlander C, Riedler J, Herz U, et al. Environmental exposure to endotoxins and its relation to asthma in school-age children. N Engl J Med 2002;347:869-77.
30. Meyts I, Hellings PW, Hens G, et al. IL-12 contribute to allergeninduced airway inflammation in experimental asthma. J Immunol 2006;177:6460-70.

31. Hoffjan S, Nicolae D, Ostrovnaya I, et al. Gene-environment interaction effects on the development of immune responses in the 1st year of life. Am J Genet 2005;76:696-704. 